\title{
POSTGRADUATE ART AND DESIGN LEARNERS AND SOCIAL SCIENCE RESEARCH METHODOLOGIES: A LEARNER-CENTRED APPROACH
}

\author{
Nicos Souleles \\ Cyprus University of Technology, Art + Design: elearning lab (CYPRUS)
}

\begin{abstract}
Challenges associated with teaching social science research methodologies include a general absence of learner interest, and the difficulty of communicating related abstract concepts that are often difficult for learners to comprehend. The lack of agreement on what methodologies are suitable for art and design compounds the challenge. The purpose of the instructional initiative is to: a) implement a learner-centred approach, and $b$ ) to make the subject relevant to the disciplinary interests of the learners. The classes entails the use of moveable chairs that allows learners to break into groups, and access to an AV projector so that each group can make their weekly presentation. The thirteen-week long unit of study is divided into themes covering a different methodology each time. The learners form groups that consist of two to three in each, and each group selects a different methodology to present to the rest of the class each week. To make certain that learners who are not presenting on a given week engage with the sessions, the rest of the class prepare and submit for evaluation three questions per group on the methodology presented to them. After the completion of each weekly presentation, these questions are used to encourage in-class discussion. Lastly, each group identifies and presents one academic paper related as much as possible to art and design on the research methodology under discussion. The challenge for the lecturer is to prepare relevant questions each week and identify case studies to have ready in case the learners do not progress with the in-class discussion. A phenomenological study of the overall learner experience indicated that the majority of learners enjoy the classes. This is corroborated by anonymous feedback provided by the learners. The lecturer gauges learning through the weekly formative assessment of the questions the learners ask and the examples they present, as well as how these are presented, articulated, and discussed during the class. Lastly, to improve the unit the learners proposed the presentation of their own research proposal each week based on their respective disciplinary interests.
\end{abstract}

Keywords: Art and design, research methodologies, teaching and learning.

\section{INTRODUCTION TO THE SPECIFIC OBJECTIVES OF THE TEACHING INITIATIVE}

At the Department of Multimedia and Graphic Arts at Cyprus University of Technology, the unit 'Research Methodologies' is compulsory for all programs of study at the postgraduate level, including doctoral learners. The objective of this semester-long unit (13 weeks) is to expose learners to the ontological, epistemological, and methodological aspects associated with the most common research paradigms in the social sciences, and assist learners to identify with and chose methodologies that are closely associated with their own individual design interests and practices.

The learning outcomes - as listed in the module outline - state that upon successful completion of the unit of study, learners are expected to:

a) be able to communicate an understanding of different social science research methodologies, including the principles, epistemological methods, limitations, and associated advantages and disadvantages;

b) be able to consider the purpose of different research methodologies and select the appropriate one for specific projects;

c) understand the process of data gathering according to the requirements of the different research methodologies covered by the unit of study; and lastly

d) know the ethical issues associated with the respective research methodologies.

The unit is divided into weekly themes covering a different research methodology each time. During the first class, the learners form groups among themselves that consist of two to three members each. 
Each group selects a methodology to present each week to the rest of the class. The choices that the groups select from and present in 45 minutes each week, are: case studies, surveys, experiments, ethnography, phenomenology, phenomenography, grounded theory, action research, content analysis, quantitative research, mixed methods, discourse analysis, symbolic interactionism and feminist methods. During the first session of the unit, all the relevant readings for each week are provided to the learners in digital form (pdfs).

To make certain that learners who do not present on a given week will engage with the learning process during the class, each group prepares and submits for evaluation three questions on the research methodology presented to them each week. In addition, each group identifies and brings to the class one paper on the methodology under discussion. For example, in a class of six groups this would add an additional six different case studies (readings) each week to assist the discussion part of the weekly session. After the completion of each weekly presentation, copies of the group questions together with the case studies from each group are circulated among all learners, and these used as a trigger to stimulate in-class discussion. Thus, the instructional approach (group choice of research theme, learner presentations, group questions and class discussions) is planned to be learner-centred and to promote collaboration, while the lecturer facilitates the process during each session (Figure 1). The final summative assessment entails the grading of: a) the group presentation (50\%), b) the group questions (25\%), and c) the group case studies for each week $(25 \%)$.

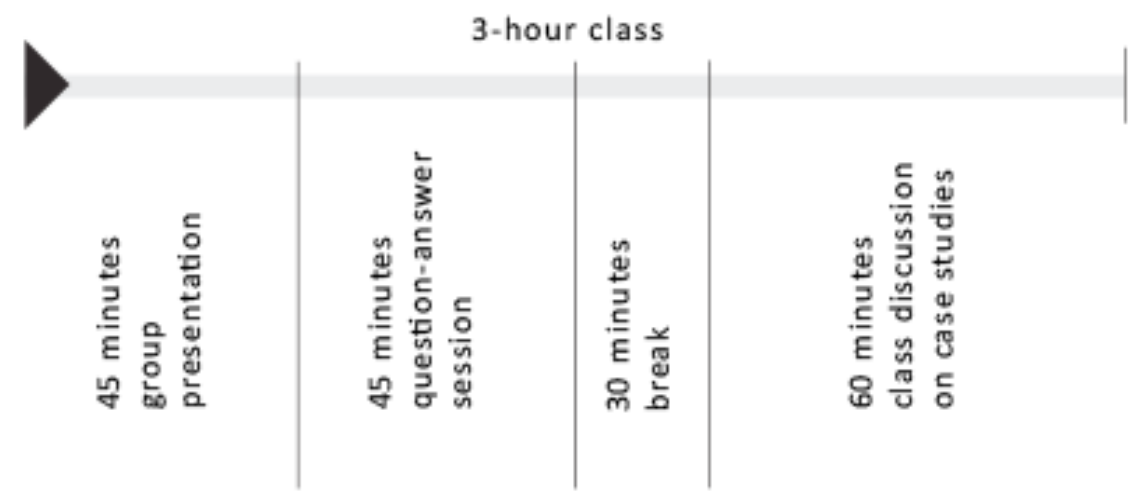

Figure 1: Breakdown of lesson time.

\section{THE INFRASTRUCTURE}

To facilitate effectively the process described above, i.e. group presentations to the class, the break down into groups for the question-answer sessions following the group presentation, and the ensuing discussion, it is essential to have access to a classroom with a sufficient number of moveable chairs that double-up as mini desks (Image 2). During the first part of the lesson, all chairs are facing the front of the classroom (Image 3) where a different group each week makes their presentation with the help of an AV projector. During the second part of the lesson - the question-answer and discussion part - the chairs are grouped together into the groups that were determined during the first session of the unit (Image 4).

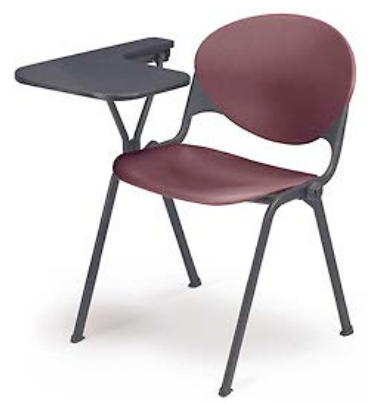

Image 2: Moveable chair with a mini desk. 


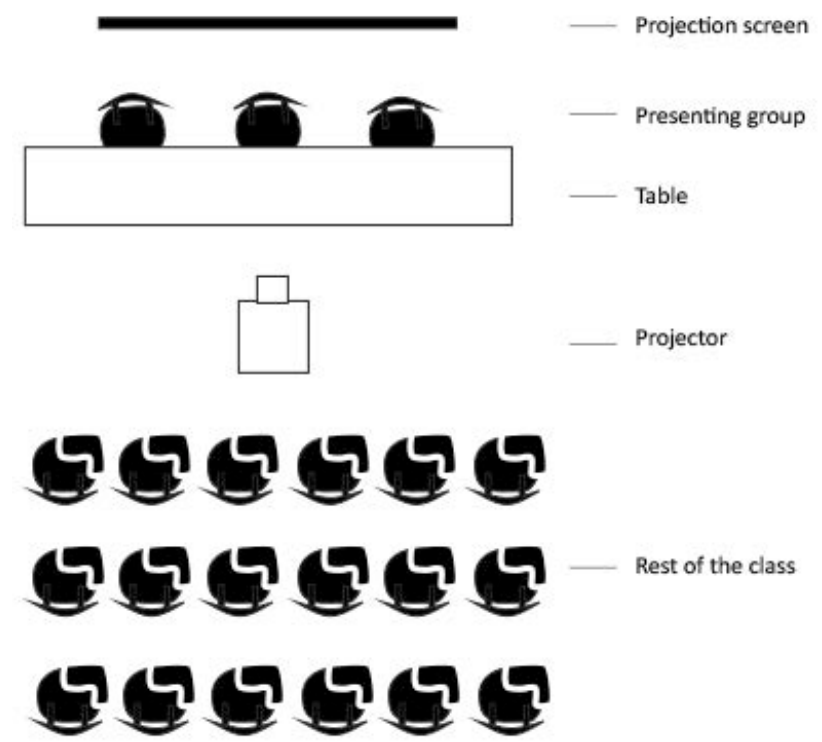

Image 3: The arrangement of chairs during the first part of class. They are facing the presenting group.

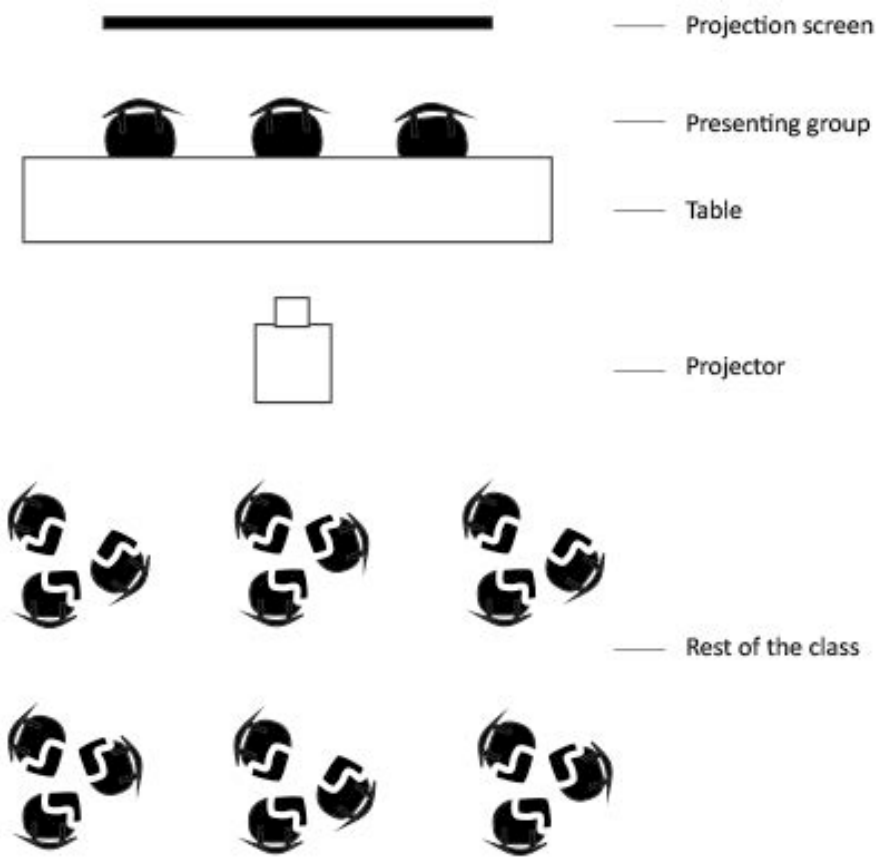

Image 4: The arrangement of chairs during the second part of the class, break down into groups.

\section{THE CHALLENGES}

The challenges associated with teaching research methodologies in Higher Education (HE) include a general lack of learner interest in the topic, and the difficulty learners have in understanding associated concepts that are often abstract and difficult to communicate (Ransford \& Butler 1981, p. 291; Braguglia \& Jackson 2012, p. 348; Carty, 2007, p. 98). In addition, there is also lack of agreement in academia on which research methodologies are appropriate for art and design disciplines. Due to the latter, it is challenging to present research methodologies to art and design learners as relevant to their practice. The lack of widespread agreement on what research methodologies are appropriate for art and design is attributed to the relatively recent transition of the related disciplines from vocational education to the academic traditions of the university (Feast \& Melles 2010, p. 1; Durling, 2002, p. 80). However, Yee and Bremner (2011) suggest that during the last decade the landscape of design research has increasingly changed due to a shift from nondesigners asking research questions, to designers themselves asking such questions. Due to this 
gradual change, there is a relatively recent interest in research methodologies in art and design (Muratovski, 2016).

To address the above two interrelated challenges, i.e. to make it easier for learners to better comprehend - as much as possible - the abstract terms associated with research methodologies, and at the same time make the unit relevant to their academic interests, the groups identify one case study each on the methodology under discussion each week ( $25 \%$ of the overall grade). In other words, each group has to search for academic papers that relate to art and design and communicate how the research methodology was used. If the groups have difficulty to identify such papers, for example it is difficult to find papers on grounded theory and art and design, then the groups are allowed to present another paper that is of interest to them, as long as this relates to the methodology under discussion.

Subsequently, and before each class, the members of each group spend some time searching through various academic databases for relevant case studies, collaborating and negotiating among the members of the group on the appropriateness or not of the chosen case study, deciding on what to present to the class, and then working on how to explain and defend their choice. Some examples of case studies that the learners identified, presented and discussed in 2015, are 'Essential facts about the computer and video game industry: 2015 sales, demographic and usage data' [survey] (Entertainment Software Association, 2015), 'Action research approach on mobile learning design for the underserved' [action research] (Kim, 2009), and 'ASCIT sick children: Again at my School by fostering communication through interactive technologies for long term sick children' [case study] (Fiore, Jorissen, Van Reeth, Lombaert, Valcke, Vansichem, \& Hauttekeete, 2008).

The challenge for the lecturer is to prepare for each weekly lesson relevant and interesting questions, and to identify case studies to have ready in case the learners do not progress with the in-class discussion. It is fair to argue that this challenge has become easier to deal with because over the years and with significant input from the learners, a collection has developed of questions, representative case studies based on the related disciplines, and even YouTube videos for each research methodology - all fertile material to encourage and support in-class discussions.

\section{HOW THE INITIATIVE WAS RECEIVED BY THE LEARNERS}

During the first lesson of the unit a considerable amount of time is spent to explain how the instructional approach is structured, what the educational objectives are, how the learners are expected to participate and how they will be assessed. Also, during the same lesson and after the structure of the lessons is described, general theoretical terms that are applicable to all research methodologies are explained extensively, i.e. terms such as ontology, research paradigms, inductive and deductive logic, epistemology, internal validity, external validity, transferability and ethics. This is the only time that the learners are expected to keep notes.

It has been observed that a common initial response among the learners is one of bewilderment; in the majority of cases, they expect a traditional teacher-centered approach where the lecturer talks and the learners take notes in every lesson. In time, and after two-three weekly sessions, the learners become accustomed to the structure of the learning experience, and it is observed that overall and gradually their participation and interest in the subject tend to increase. It also helps the instructional process if the groups become competitive and, when convenient, the lecturer may encourage this.

In 2015, the author together with his doctoral student undertook a phenomenological study to find out how the learners considered the experience of learning social science research methods within the perspective of the adopted learner-centred approach (Souleles \& Perdiou, 2015). Purposive sampling was used to select the eleven participants (nine female and two male learners), who were interviewed - after they offered their informed consent - from a class of seventeen postgraduate graphic design students undertaking the unit on research methodologies. Purposive sampling is useful for situations where one needs to reach a targeted sample quickly and where sampling for proportionality is not the concern. The common characteristic of the participants was that they all completed the thirteen-weeklong unit of study and were willing to be interviewed about their shared experience. The number of interviewees was a little higher than the maximum of ten recommended by Groenewald (2004, p. 11).

Based on the phenomenological analysis pursued in this study, a number of inferences were possible. Firstly, although the learner-centred approach to the teaching of social sciences research methodologies was overall a welcome and positive experience for most learners, there were some who felt uncomfortable and preferred a more teacher-centred approach. The learners, who considered in a positive manner the teaching and learning strategy and indicated their preference for active 
learning, belong to the same group whose experience included an understanding of abstract and theoretical concepts associated with social science research methodologies. Lastly, even though subjectivist epistemologies are prevalent in art and design (practice is de factor research), the teaching of social sciences research methods to the particular group of postgraduate graphic design students generated for some the inclination to use these methodologies for their practice and in the context of a number of different design-related applications.

In addition to the above study, the anonymous evaluations that the learners provide at the end of all units of study indicate that over the last four years the majority is satisfied with the learning experience. Overwhelmingly, the learners continue to provide anonymous positive feedback, and have even made suggestions on how to improve the unit further.

\section{ASSESSING THE LEARNING OUTCOMES}

The development of learning outcomes is an inherently difficult task because it is challenging to comprehensively define them in a manner that reflects and caters for the abilities of diverse learners (European Commission, 2011, pp. 6-7). In addition, the difficulty is compounded, because art and design comprises mostly of low paradigmatic disciplines. In other words, there is little agreement among the academics of the sector about theory, methods, and techniques. In contrast, biology, chemistry, physics, and the sciences represent high paradigmatic development disciplines (Braxton, Olsen \& Simmons, 1999, p. 301).

Consequently, and due to the instructional strategy described above, the assessment of learning outcomes entails continuous formative assessment by the facilitator (lecturer). There is ample opportunity during each weekly session to informally assess which learners participate, how wellinformed their questions are, how well they understand related concepts and how well they are able to communicate the latter. Thus, within the context of the learner-centred approach described above, evaluation of learning outcomes is an on-going process. The final three submissions for summative evaluation (group presentation, group questions and group case studies) effectively represent a confirmation of what was learnt, rather than a last minute articulation and expression of everything the learner mastered. Lastly, upon completion of the unit of study, all learners receive written feedback in relation to the above four learning objectives, and this is informed by the notes and observations made by the lecturer (facilitator) on a weekly basis throughout the duration of the unit of study.

\section{$6 \quad$ PLANS TO FURTHER DEVELOP THE INITIATIVE}

Ideally, improvements to the unit of study should be informed by feedback received from the learners. Thus, they are encouraged to come up with different ideas on how the instructional approach - and this includes assessment - can become more engaging and effective. One can fine-tune the breakdown of lesson time (Image 1), and/or make minor adjustments on a regular basis depending on the weekly response of learners. However, the desired development is on how to further improve the overall instructional approach. To this end, and following on from feedback received from the learners last year, next academic year each group will be asked to develop an outline on how they could use the weekly research methodology under discussion in relation to their own design interests. In other words, each group will attempt to associate each research methodology to an area of their own interest and describe how they could use it. The potential benefit of this approach is that it makes the unit even more relevant to their disciplinary interests. Whether this will become a fourth assessment, or replace an existing one, has not been determined yet. However, if a unit of study is to further improve over time, then it is useful to always approach it as a participatory action research exercise with continuous loops of improvement. In this context, the facilitator has an opportunity to continuously learn from the learners.

\section{REFERENCES}

[1] Braguglia, K. H. \& Jackson, K. A. (2012). Teaching research methodology using a project-based three course sequence critical reflections on practice. American Journal of Business Education, 5(3), 347-352.

[2] Braxton, J., Olsen, D. \& Simmons, A. (1999). Affinity disciplines and the use of principles of good practice for undergraduate education. Research in Higher Education, 39(3), 299-318. 
[3] Carty, R. (2007). Teaching research methods: a pragmatic approach. Investigations in university teaching and learning, 4 (2), 98-105.

[4] Durling, D. (2010). Discourses on research and the PhD in Design. Quality Assurance in Education, 10(2), 79-85.

[5] Entertainment Software Association. (2015). Essential facts about the computer and video game industry: 2015 sales, demographic and usage data (Entertainment Software Association, Washington, DC).

[6] European Commission (2011). Using learning outcomes. European Qualifications Framework, Note 4. Luxembourg: Publications Office of the European Union.

[7] Feast, L. \& Melles, G. (2010). Epistemological Positions in Design Research: A Brief Review of the Literature (pp. 1-5). Proceedings of the 2nd International Conference on Design Education. Sydney, Australia: University of New South Wales.

[8] Fiore, F. D., Jorissen, P., Van Reeth, F., Lombaert, E., Valcke, M., Vansichem, G., \& Hauttekeete, L. (2008). ASCIT sick children: Again at my School by fostering communication through interactive technologies for long term sick children. Journal of Advanced Technology for Learning, 5(1), 68-78.

[9] Groenewald, T. (2011). A Phenomenological Research Design Illustrated. International Journal of Qualitative Methods 3(1), 1-26.

[10] Kim, P. H. (2009). Action research approach on mobile learning design for the underserved. Educational Technology Research and Development, 57(3), 415-435.

[11] Muratovski G. (2016). Research for designers: A guide to methods and practice. Los Angeles, USA: SAGE Publications.

[12] Ransford, E. \& Butler, G. (1982). Teaching research methods in the social sciences. Teaching Sociology, 9(3), 291-312.

[13] Souleles, N., \& D. Perdiou (2015, July). Postgraduate graphic design students and social science research methods: a phenomenological investigation of a student-centred learning experience. Paper presented at EDULEARN15 Conference, Barcelona, Spain.

[14] Yee, J. \& Bremner, C. (2011). Methodological bricolage: What does it tell us about design? Proceedings of the 2011 Doctoral Design Education Conference. Hong Kong: Hong Kong Polytechnic. 